\title{
Lionel W. Young, MD, FACR (1932-2019)
}

\section{Tina Young Poussaint ${ }^{1}$}

Received: 17 April 2019 / Accepted: 29 April 2019 / Published online: 17 May 2019

(C) Springer-Verlag GmbH Germany, part of Springer Nature 2019

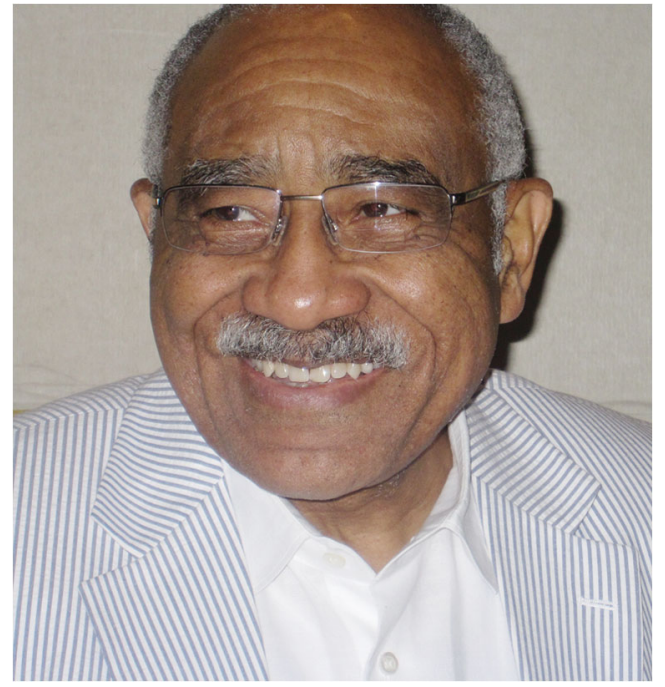

Dr. Lionel W. Young, esteemed pediatric radiologist, colleague, mentor, beloved husband, father and grandfather, was born in New Orleans, LA, on March 14, 1932, and died April 10, 2019, in Redlands, CA, from complications of heart disease.

Dr. Young received his Bachelor of Science degree from Benedictine College (1953) in Atchison, KS, and his Doctor of Medicine degree from Howard University College of Medicine (1957). Dr. Young completed a rotating internship at Detroit Receiving Hospital, Wayne State University College of Medicine, and then applied for residency in radiology.

He was accepted into radiology training at Strong Memorial Hospital in Rochester, NY. During his residency he became especially interested in the application of

Tina Young Poussaint

tinayoung.poussaint@ childrens.harvard.edu

1 Department of Radiology,

Boston Children's Hospital,

300 Longwood Ave., Boston, MA 02115, USA diagnostic and therapeutic radiology to diseases of children and decided to seek additional training in pediatric radiology. However, the Berry Plan, which had deferred his draft into the U.S. military until completion of residency training, temporarily delayed his quest to study pediatric radiology. As a lieutenant commander in the U.S. Navy, he was assigned to be chief of radiology for 2 years at the Portsmouth Naval Hospital in New Hampshire. Lt. Cmdr. Young supervised the diagnostic imaging and radiation therapy needs of Navy and Air Force personnel and their dependents.

Following Dr. Young's discharge from the Navy, Dr. Frederic Silverman, a pediatric radiologist at Cincinnati Children's Hospital, became Dr. Young's mentor, supported by a 2-year fellowship grant for training in clinical pediatric radiology. In Cincinnati, Dr. Young was also inspired to teach and engage in relevant associated research.

Dr. Young returned to Strong Memorial Hospital at the University of Rochester to establish its first pediatric radiology section and to begin a fellowship training program, obtaining yearly grants for the trainees. Dr. Young's success at Rochester from 1965 to 1975 led to his appointment as director of pediatric radiology at Children's Hospital of Pittsburgh. The radiology staff at Pittsburgh included Dr. John Caffey, the pioneer pediatric radiologist who had mentored Drs. Frederic Silverman and Dr. Bertram Girdany at Babies Hospital in New York.

A particular delight at Pittsburgh Children's Hospital was a visit from Fred Rogers of the children's television show Mister Rogers' Neighborhood. Dr. Young participated in a segment of "Let's Talk About the Hospital" that included a radiograph of a boy's arm. Dr. Young pointed out the findings of a fractured radius and discussed the imaging technique. That video remains accessible on PBS replays of Mister Rogers' Neighborhood.

In 1985, Dr. Young left Pittsburgh to direct radiology at Akron Children's Hospital and to be a professor and chairman of radiology at Northeastern Ohio Universities College of Medicine. He left that position in 1991 to take on the challenge of developing a pediatric radiology department at the new Loma Linda University Children's Hospital. He served as 
a professor of radiology and head of pediatric radiology. He served on the Loma Linda University graduate medical education committee and as chairman of the radiology academic advisory panel.

Highlights of Dr. Young's academic record include more than 200 publications (journal articles and book chapters), as well as more than 50 visiting professorships in the United States and abroad, including several at American universities (Harvard, Yale, Stanford, Howard, Johns Hopkins, University of California-Los Angeles, Indiana University, University of Iowa, University of Michigan and University of Oregon). In 1969, Dr. Young was the recipient of the first John P. Caffey Award from the Society for Pediatric Radiology for his paper titled "Pneumonia of atypical measles: residual nodular lesions."

Dr. Young served as president of the Society for Pediatric Radiology (1984-1985) and a member of the Diagnostic Radiology Study Section of the National Institutes of Health (1987-1991). He was elected to the Gamma chapter of Alpha Omega Alpha Honor Medical Society (1988). He received the Distinguished Service Award for 25 years as examiner for the American Board of Radiology (2000). He was a fellow of the American College of Radiology, a fellow of the American Academy of Pediatrics, and an emeritus member of the Board of Directors of Benedictine College. Dr. Young was a devoted member of the John P. Caffey Pediatric Radiology Society. He especially cherished two awards for Distinguished Postgraduate Achievement in the Field of Medicine from Howard University. Dr. Young was honored to have his name attached to the annual symposium on pediatric radiology for the Section on Radiology and Radiation Oncology of the centuries-old National Medical Association. Dr. Young was also an active member of the Sigma Pi Phi Fraternity, the first successful and oldest African-American fraternity known as the Boule.
Dr. Young was a nationally and internationally recognized leader in pediatric radiology who was respected and loved by trainees and colleagues. He loved teaching and learning with medical students, residents and pediatric radiology fellows everywhere he practiced. He retired in fall 2018 from Loma Linda after a career that provided a continuous pattern of challenge and growth for the provision of care for children. Under his leadership, he oversaw the growth and expansion of pediatric radiology wherever he worked.

Dr. Young noted that it was a wonderful challenge to experience the enormous growth in the 21st century of diagnostic radiology and imaging technology that benefits children and adults. He found teaching and learning with trainees helped to keep him "young."

Dr. Young is survived by his wife, Florence, the love of his life for 61 years; his daughter Dr. Tina Young Poussaint and sonin-law Dr. Alvin F. Poussaint; his son Mr. Lionel Thomas Young; his son Mr. Owen C. Young and daughter-in-law Valerie Sullivan Young; his five granddaughters: Grace Young, Alison Poussaint, Cecilia Marrinan, Sadie Young and Clara Young; his step-grandson: Alan M. Poussaint; his cousin, Dr. Wilbert R. Sykes, and his nieces and nephews from the Lancaster family. He is predeceased by his parents Mr. and Mrs. Charles Young; his brother Dr. Charles Young; and his two sisters: Mrs. Doris Young Lancaster and Ms. Vera Mae Young.

Dr. Lionel W. Young was a brilliant pediatric radiologist who was a champion for the health of children. He loved his family deeply, was a cherished friend and colleague and had a strong faith in God. He will be greatly missed by all who knew and loved him.

Publisher's note Springer Nature remains neutral with regard to jurisdictional claims in published maps and institutional affiliations. 